\title{
Determinants of growth monitoring and promotion service utilization among children 0-23 months of age in Northern Ethiopia: Unmatched case control study
}

\section{Samuel Dagne Chanie ( $\nabla$ samdagseg@gmail.com )}

Bahir Dar University College of Medical and Health Sciences

Jemal Aliyu Yimam

Bahir Dar University College of Medical and Health Sciences

Yonatan Menber Antigegn

Bahir Dar University College of Medical and Health Sciences

Yosef Wassihun Mengistie

Bahir Dar University College of Medical and Health Sciences

Netsanet Fentahun Bayabel

Bahir Dar University College of Medical and Health Sciences

\section{Research}

Keywords: Growth Monitoring and Promotion, under two years' children, Legambo District, Northern Ethiopia

Posted Date: September 1st, 2020

DOI: https://doi.org/10.21203/rs.3.rs-63983/v1

License: (c) (i) This work is licensed under a Creative Commons Attribution 4.0 International License.

Read Full License 


\section{Abstract}

\section{Back ground}

Child malnutrition is one of the world's public health problems. Promotion of child growth and development is one of the health priorities to control child mortality and poverty reduction. One of the strategies to promote child health is growth monitoring and promotion services. But, there is limited information on determinants of Growth Monitoring and Promotion service utilization.

\section{Objective}

To identify determinants of growth monitoring and promotion (GMP) service utilization among children 0-23 months of age in Legambo district, South Wollo zone, Northern Ethiopia, 2020.

\section{Methods}

Community based un-matched case control study was conducted on 363 (91 cases and 272 controls) study participants from March 15 to April 15, 2020.. Multi-stage sampling technique was employed to select the study participants.. Data were collected by using interviewer administered questionnaire and entered in to Epi data and exported to SPSS version 23 for analysis. Bivariable and multivariable logistic regressions were performed and adjusted odds ratio with $95 \%$ confidence intervals was estimated to identify determinants of GMP service utilization.

Results

Good maternal knowledge $(\mathrm{AOR})=2.42 ; 95 \% \mathrm{Cl}: 1.23,4.75)$, mother with favorable attitude $(\mathrm{AOR}=2.45$; $95 \% \mathrm{Cl} ; 1.20,4.98)$, counseling on GMP (AOR $=2.34 ; 95 \% \mathrm{Cl} ; 1.19,4.56)$, Attending ante natal care services $(A O R=2.46 ; 95 \% \mathrm{Cl}: 1.18,5.16)$, index child age $12-17$ months $(A O R=3.45 ; 95 \% \mathrm{Cl}: 1.26,9.41)$ and $18-23$ months ( $\mathrm{AOR}=4.38 ; 95 \% \mathrm{Cl}: 1.53,12.49)$, and short distance to health facilities ( $\mathrm{AOR}=4.53$; $95 \% \mathrm{Cl} ; 1.99,10.28)$ were determinants of GMP service utilization.

Conclusions and recommendation

Index child age, good knowledge, favorable attitude, attending ante natal care services, receiving nutritional counseling and short distance to health facility were determinants of GMP service utilization. Nutritional interventions should emphasis nutritional counseling, utilization of ANC service and accessibility of growth monitoring and promotion service to improve growth monitoring and promotion service utilization and reduce malnutrition in Ethiopia

Trial registration

No applicable

\section{Introduction}


Child malnutrition is one of the world's serious public health problems. Around $45 \%$ of deaths among children under 5 years of age are linked to under nutrition [1]. Worldwide, 151 million under-five years of age children were stunted, 51 million were wasted, and 52 million were overweight[2]. Child malnutrition is also still a high public health problem in Ethiopia. According to the 2019 Ethiopian mini Demographic and Health Survey (EDHS) report, the prevalence of stunting was $37 \%$, underweight $21 \%$, and wasting $7 \%$ [3]. Similarly the prevalence of stunting in Amhara region was $41 \%$ which was the third highest from the regions of the country[3]

Poor child growth and development in the early stages of life can increase risk infections, morbidity, and mortality together with decreased mental, cognitive and economic development [4-6]. Promotion of child growth and development is one of the health priorities to control child mortality and poverty reduction [7]. Even though Growth Monitoring and Promotion (GMP) is one of the prerequisite for good child health, several studies showed that there is a big difference between the purpose and the practice of GMP[8, 9]. The high prevalence of malnutrition in many low and middle income countries including Ethiopia supports this fact $[3,10,11]$. Participation in GMP remains relatively low in Ethiopia. A research findings from Southern Ethiopia showed that the coverage of GMP service utilization was $16.9 \%$ in Mareka district [12], and $11 \%$ in Butajira [13].

Previous studies reported that socio-demographic, maternal and health professional related factors influences GMP service utilization [12-18].

The National Nutritional Program (NNP) of Ethiopia considers GMP as one of the strategies for improving the nutritional status of the children and has been implementing at community level through health extension programs. GMP is a prevention activity comprised of GM linked with promotion that increases awareness about child growth; improves caring practices; increases demand for other services, as needed; and serves as the core activity in an integrated child health and nutrition program [9]. Promoting and improving child health during the window of opportunity period starting from conception to a child's second birthday, is crucial for survival [19].

Even though Ethiopian government has been implementing GMP services at community level, the available data indicated that malnutrition is still high and participation in growth monitoring remains relatively low in the country. There is limited evidence on determinants of Growth Monitoring and Promotion service utilization in Ethiopia. The aim of this study was to identify determinants of GMP utilization among children less than two years in Legambo District, South Wollo zone, Northern Ethiopia. Therefore, identifying the determinants of low coverage of GMP service utilization helps nutrition program implementers to design evidence based GMP intervention.

\section{Materials And Methods}

\section{Study area and period}


The study was conducted from March 15 to April 15, 2020 in Legambo District, South Wollo zone, Northern Ethiopia. The district is found in South Wollo zone Amhara region. it is situated on the beautiful highlands of south Wollo at an altitude of about 3000 meters above sea level and is located 100 kilometers to Dessie (the capital city of South Wollo zone), 430 kilometer from Bahirdar (the Capital city of Amhara region) and $501 \mathrm{~km}$ far from Addis Ababa (the Capital city of Ethiopia). The district has 33 health Posts, 9 health center, 1 hospital, 78 Health extension workers. The total population of the district was 281,974 with 147,160 males and 134,748 females while the total number of children with age of o month to 23 months was 10,172 in the year 2017 which was projected from the Woreda Administration office[20]

\section{Study design}

A community based un-matched case control study design was employed.

\section{Eligibility criteria}

All mother-child pairs with 0-23 months reside in Legambo district during the study period were included in the study. Whereas, children with the age of 0 to 23 months suffering from chronic illnesses and those on treatment such as TB, HIV were excluded from the study.

\section{Sample size determination}

The sample size was calculated using Epi Info version 7.2.1.1 by considering the following assumptions: proportion of reach wealth status who utilized GMP service was $19.5 \%$ among controls and $5 \%$ among cases from the study conducted in Southern Ethiopia, 5\% type I error, $80 \%$ power, $1: 3$ cases to controls ratio, design effect of 1.5 and $10 \%$ non-response [12]. The final sample size was 363(91 cases and 272 controls).

\section{Sampling procedures}

A multi-stage sampling technique was used to select the study participants. Out of 34 kebeles in the district, 7 kebeles were selected using lottery method. The list of mother-child pairs aged 0-23 months and their house numbers from each kebele were obtained from the health extension workers. House to house censuses were made to identify cases and controls and children aged 0-23 months were identified and registered sequentially and had got identification number as case and control. And then, the total sample size was allocated proportionally to each kebele. Finally, both cases and controls were selected by simple random sampling technique.

\section{Data collection tools and procedures}

The data were collected using interviewer administered structured questionnaire. The questionnaire includes socio demographic, economic, health care, behavioral factors and maternal/caregiver's related 
characteristics and adapted from previous studies[12, 13, 16, 21, 22] and collected by well trained and experienced two clinical nurses and three diploma midwifes and three health officer supervisors.

ANC visit was assessed based on the basis of the minimum recommended visits (yes; for having four or more visits and no; for less than four visits). And, PNC was also assessed by on the basis of the minimum recommended visits (yes; for having at least one visit in the post-partum period and no; for not visits at all). Vaccination status of children was checked by observing immunization card and if not available mothers /caregivers/ were asked to recall it. BCG vaccination was checked by observing scar on right (also left) arm. Wealth index was computed by owner ship of different asset, house characteristic and type of latrine and water source. The resulting wealth index was categorized into three as low, medium and high[10]. Distance to health facility determined by the distance (time taken to reach the health facility from mothers' home to the nearest health facility). Distance to health facility was classified as less than one hour and more than one hour to reach the nearest health facility[23]. Knowledge of mothers towards GMP service utilization was assessed using ten knowledge questions. Each questions has two response (yes $=1$ or $0=$ no). The total score ranges from 0 to 10 . Score below 7 categorized as poor knowledge (21). Attitude of mother to GMP service was assessed by 12 attitude questions using likert scale measures. The total score ranges from 12 to 60 . Score of $<75 \%$ was categorized as unfavorable attitude [13].

\section{Data quality assurance}

The questionnaire was translated to Amharic language and translated back to English to ensure consistency. The questionnaire was pre-tested in $5 \%$ of the sampled population in non-selected kebeles before the actual data collection. Data collectors and supervisors were trained for two days. Test-retest reliability of the research instrument was established during pretesting. Test re-test reliability was established by examining the consistency of pre-test responses. On spot checking and correction were made for incomplete questionnaire by supervisor. The overall data collection process was controlled by the principal investigator.

\section{Data processing and analysis}

The data were coded and entered and into Epi info version 7 and exported to SPSS version 23 for analysis. Descriptive statistics were computed and presented using tables, figures and charts. Model goodness of fitness was assessed by using Hosmer and Lemeshow test. Multi- colinearity between independent variables was checked. Bi-variable logistic regression was executed and variables with $p<$ 0.25 were fitted to the final multivariable logistic regression to adjust for potential confounders. In the final model, variables with P-value $<0.05$ and AOR of $95 \% \mathrm{Cl}$ were considered to declare the statistical significant and the strength of association

\section{Results}

\section{Socio- economic characteristics of study participants}


A total of 358 mothers (89 cases and 269 controls) with $98.6 \%$ response rate were included in the study. The mean age of mothers was 27.28 with SD of \pm 5.074 . The average family size was 4.4 with SD of \pm 1.50. About $55(61.8 \%)$ and $150(55.8 \%)$ of respondents were farmers among case and controls, respectively (Table 1).

\section{Growth Monitoring and Promotion service and child age}

High utilization of GMP observed in both cases and controls in the age group of 12-17 months age, $35(39.3 \%)$ and $74(27.5 \%)$, respectively. While low utilization of GMP service utilization was reported among cases $7(7.9 \%)$ within the age group of $0-5$ months of age (Fig. 1).

\section{Maternal knowledge and attitude to GMP service}

Around $72(80.9 \%)$ of cases and $133(49.4 \%)$ of controls group had good knowledge. Regarding the attitude; ( $83.1 \%$ of cases and $48 \%$ of controls) had favorable attitude. About $16(18 \%)$ of cases and $32 \%$ of controls don't know when the growth monitoring service is started (Table 2).

\section{Health care service related characteristics}

About 74(83.1\%) mothers in cases group (utilized) and 132(49.1\%) mothers/caregivers in the controls group (Non- utilized) had 4 and above antenatal care (ANC) visits. Majority of mothers/caregivers in both cases group (67.4\%) and controls group (71\%) gave birth (for this baby) in health institutions. Only $70(78.7 \%)$ mothers in case groups and $123(45.7 \%)$ mothers in control group were counseled on GMP (Table-3).

\section{Determinants of GMP service utilization}

In the Bivariable regression analysis, child age, paternal education, maternal education, antenatal care utilization, counseling on GMP service utilization, postnatal care utilization, knowledge, attitude, service quality, access to media and distance to health facility were associated with the GMP. Variables with a pvalue $<0.25$ were transferred to multivariable logistic regression. Child age, knowledge, attitude, counseling on GMP, ANC service utilization and distance to health facility were independent predictors of GMP service utilization at $p$-value $<0.05$.

Mothers/caregivers who had good knowledge were 2.4 times more likely utilize GMP service compared to mothers/caregivers who had poor Knowledge $(\mathrm{AOR})=2.42 ; 95 \% \mathrm{Cl}: 1.23,4.75)$.

Mothers/caregivers who had received counseling on GMP service were 2.3 times more likely utilize GMP service compared to mothers/caregivers who had not received counseling (AOR $=2.34,95 \% \mathrm{Cl}$ : 1.19, 4.56). Mothers/caregivers who reached near by the health facility less than one hour were 4.5 times more likely to utilize GMP service as compared to mothers/caregivers who reached greater than one hour (AOR $=4.53 ; 95 \% \mathrm{Cl}: 1.99,10.28)$.

Mothers/caregivers who had utilized ANC services were 2.46 times more likely to utilize GMP services as compared to mothers/caregivers who had not utilized ANC services (AOR $=2.46 ; 95 \% \mathrm{Cl}: 1.18,5.16)$. 
Mothers/caregivers/ who had favorable attitude were 2.45 times more likely to utilize GMP services as compared to unfavorable attitude(AOR $=2.45 ; 95 \% \mathrm{Cl}: 1.20,4.98)$.

Mothers who have children age group between 12-17 months were 3 times and 18-23months age groups were 4 times more likely to utilize GMP services as compared to who have Children with $0-5$ age groups $(A O R=3.45 ; 95 \% \mathrm{Cl}: 1.26,9.41)$ and $(\mathrm{AOR}=4.38 ; 95 \% \mathrm{Cl}: 1.53,12.49)$, respectively (Table 4$)$.

\section{Discussions}

This study aimed to identify determinants of Growth monitoring and promotion service utilization using unmatched case control study among less than two years children and the study will generate information to the Ministry of Health and other organizations working in the child survival programs to design interventions to improve the activities of GMP.

The study pointed out that determinants of growth monitoring and promotion service utilization were index child age, maternal knowledge, maternal Attitude, utilization of ANC services, getting counseling about GMP and distance to reach the nearest health facility.

Mother who had adequate knowledge of growth monitoring was more likely utilizes GMP than mother who had inadequate knowledge. Similar finding was reported from the study done in Areka town, Butajira, Kenya, and Ghana $[13,15,21,22]$. This can be explained by mother with adequate knowledge may able to understand the information displayed on the growth chart and that motivates to utilize GMP session.

In this study, child in the age group of 6-11 months and 12-23 months found that more likely to utilize GMP services as compared to infants in the age group of 0-5 months. This finding is similar with study done in Southern Ethiopia Mareka district[12] and Butajira[21]. This could be explained in Ethiopian culture mother perceived that taking their child to the GMP session will expose their child to "evil eye". Exposing children in front of people until they started walking is not accepted by the mothers[24].

This study showed that mothers/caregivers who had favorable attitude were more likely to utilize than those who had unfavorable attitude. This finding was supported by Study on Areka town, southern Ethiopia[13]. The reason for this might be good attitude of mother's leads to happy to bring their child to the GM visits and this helps to utilize GMP session and for unfavorable attitude, one qualitative study conducted Loko Abaya District, Southern Ethiopia[24] showed that Mothers mentioned that they understood GMP as being used only for unhealthy (especially wasted) children. If their children are healthy and well-fed, they did not want to attend the GMP program.

According to this study mothers who utilized ANC services were more utilize GMP services than those who had not ANC service utilization. The possible justification for this may be during Ante natal care nutritional counseling is given and most of the mothers understand the service that was get from the health institution and after delivery the mothers will be happy to attend GMP session. This result is different from study done in Mareka district[12] showed that there is no significant association between 
Utilization of ANC services and GMP service utilization. This difference is may be due to study design; the previous study was used cross-sectional while this study was used case-control study design and time difference, at this time the coverage of ANC is increased.

This study identified that mothers/caregivers who received counseling about growth monitoring and promotion were more likely to utilize GMP services than who did not received counseling. This study is in line with study in Kenya[15] which showed mothers/caregivers who received nutrition advice alongside GM services were more likely to participate in continued. The reason for this may be counseling has greater impact on motivating mothers to attend GMP sessions.

In this study, mothers traveled less than an hour get to the nearest health facility from their home were more likely to utilize GMP services those travel more than one hour to get to the nearest health facility. This finding is similar with study in Southern Ethiopian, Mareka district[12] and also supported by the study in Kenya[15] showed that distance from respondent's home to the facility $5 \mathrm{~km}$; return journey were significantly associated with continued GM and similarly in Ghana[22] stated that distance between care givers home and the child welfare clinic is a determining factor in child welfare clinic (CWC) attendance. The possible justification for this may be due to Long distances to the health facilities may be a hindrance to the mothers to continue with growth monitoring especially if the children are looking well because of the competing roles. Socio-economic variables included in this study (marital status, occupation of mother, family size of the house hold and wealth index) were not significantly associated with GMP service utilization. This might be due to similar nature or living standard of mother was included in the study. Majority of mothers were farmers, married and lived in similar setting. As a limitation, there might be a recall bias while assessing the growth chart knowledge of the mothers, utilization of ANC service and PNC services.

\section{Conclusion}

Child age, good knowledge towards growth monitoring, favorable attitude towards growth monitoring and promotion, utilization of ANC services, counseling towards growth monitoring and promotion, and time to reach the nearest health facility within one hour were determinants of GMP service utilization. Nutritional interventions should emphasis nutritional counseling, utilization of ANC service and accessibility of growth monitoring and promotion service to improve growth monitoring and promotion service utilization and reduce malnutrition in Ethiopia.

\section{Abbreviations}

ANC: Ante Natal Care; AOR: Adjusted Odd Ratio; CSA: Central Statistics Agency; Cl: Confidence Interval; DSS: Demographic Surveillance System; EDHS: Ethiopian Demographic Health Survey; GM: Growth Monitoring; GMP: Growth Monitoring and Promotion; PNC: Post Natal Care; SD: Standard Deviation.

\section{Declarations}


Acknowledgements

We would like to thanks Bahir Dar University, data collectors, supervisors and study participants.

\section{Authors' contributions}

JA, SD and NF assisted in the conception of the study, developed the proposal, involved in the method development, analysis, interpretation of the findings and in development of manuscript. YW and YM involved in the method development, interpretation of the findings and in development of manuscript. All the authors read, revised and approved the final manuscript.

\section{Funding}

The authors declare that there is no funding source.

\section{Availability of data and materials}

Data will be available up on the request of the corresponding author

\section{Ethics approval and consent to participate}

Ethical clearance was obtained from the Institutional Review Board of College of Medicine and Health Sciences, Bahir Dar University. Official support letter was obtained from Woreda administration. Written consent was obtained from the mothers/caregivers after informing all the purpose, benefits, and risks of the study

\section{Consent for publication}

Not applicable

\section{Computing interest}

The authors declare that they have no competing interest.

\section{Authros' information}

SD, JA, YM, and NF: Department of Nutrition and Dietetics, School of Public Health ,College of Medicine and Health Sciences, Bahir dar University, P.O. Box 79, Bahir Dar, Ethiopia

YW: Department of Health Promotion and Behavioral Sciences, School of Public Health, College of Medicine and Health Sciences, Bahir dar University, P.O.Box, 79, Bahir Dar, Ethiopia

\section{References}

1. Organization WH, Malnutrition Key Facts. World Health Organization, 2018: p. 1-7. 
2. Unicef, Levels and trends in child malnutrition. 2018, eSocialSciences.

3. Institute EPH. and ICF, Ethiopia mini demographic and health survey 2019: key indicators. Maryland: EPHI and ICF Rockville; 2019.

4. Black RE, et al. Maternal and child undernutrition: global and regional exposures and health consequences. The lancet. 2008;371(9608):243-60.

5. Communication UDo., Tracking progress on child and maternal nutrition: a survival and development priority. 2009: Unicef.

6. Organization WH, Stunted Growth and Development, Context, Causes and Consequences. World Health Organization, 2017.

7. Liu Q, Long Q, Garner P. Growth monitoring and promotion (GMP) for children in low and middle income countries. The Cochrane Database of Systematic Reviews, 2017. 2017(1).

8. Ashworth A, Shrimpton R, Jamil K. Growth monitoring and promotion: review of evidence of impact. Matern Child Nutr. 2008;4:86-117.

9. Bilal SM, et al. Practices and challenges of growth monitoring and promotion in Ethiopia: a qualitative study. J Health Popul Nutr. 2014;32(3):441.

10. Ethiopia, Ethiopia Demographic and Health Survey, 2016. 2012: ICF International, c entral Statistical Agency, uly 2017.

11. Fanzo J, et al., 2018 Global Nutrition Report: Shining a light to spur action on nutrition. 2018.

12. Feleke FW, Adole AA, Bezabih AM. Utilization of growth monitoring and promotion services and associated factors among under two years of age children in Southern Ethiopia. Plos one. 2017;12(5):e0177502.

13. Daniel B, et al. Knowledge and Attitude on Growth Monitoring and its Associated Factors among Mothers/Guardians of Children Less than Two Years in Areka Town, Southern Ethiopia, 2017. J Nutr Disorders Ther. 2017;7(216):2161-0509.1000216.

14. Melkamu AW, et al. Prevalence of growth monitoring practice and its associated factors at public health facilities of North Gondar zone, northwest Ethiopia: an institution-based mixed study. BMC Pediatr. 2019;19(1):144.

15. Nyabuti Jl, Factors associated with the continuation of growth monitoring among children 1059 months old in Nyamira County, Kenya. Unpublished Masters dissertation, Kenyatta University, Nairobi, Kenya, 2015.

16. Baraki T, Gebru AA, Belay D. Knowledge attitude and practice of health extension workers towards growth monitoring and promotion program in Tigray region, Ethiopia. Eur J Biomed Pharm Sci. 2018;3(4):55-64.

17. Saaka M. Relationship between mothers' nutritional knowledge in childcare practices and the growth of children living in impoverished rural communities. J Health Popul Nutr. 2014;32(2):237.

18. Sahanggamu PD, Purnomosari L, Dillon D. Information exposure and growth monitoring favour child nutrition in rural Indonesia. Asia Pac J Clin Nutr. 2017;26(2):313. 
19. Shekar M, et al. Investing in Nutrition: The Foundation for Development-An investment framework to reach the global nutrition targets. Washington, DC: World Bank, results for development, Bill and Melinda Gates Foundation, CIFF, Thousand days; 2016.

20. office LWa., The district population projection. 2017.

21. Desalegne H, S.S., and Haile D. Assesment of knowleage and utilization of growth monitoring and promotion for under two childen in Butajira. 2017.

22. Debuo T, et al. Caregivers knowledge, attitude and practices on child growth monitoring and promotion activities in Lawra District, Upper West Region of Ghana. Science Journal of Public Health. 2017;5(1):20-30.

23. Delamater $\mathrm{PL}$, et al. Measuring geographic access to health care: raster and network-based methods. Int J Health Geogr. 2012;11(1):15.

24. Tekle M, et al., Exploring Reasons for Low Attendance of Mothers to Growth Monitoring and Promotion Program at Loka Abaya District, Southern Ethiopia: Exploratory Qualitative Study. Journal of nutrition and metabolism, 2019. 2019.

\section{Tables}

Table 1: Socio-economic characteristics of mothers/caregivers in Legambo district, South Wollo zone, Northern Ethiopia, 2020. 


\begin{tabular}{|c|c|c|c|}
\hline Variable & & Case: $n=89(\%)$ & Control: $n=267(\%)$ \\
\hline \multicolumn{4}{|l|}{ Maternal age } \\
\hline & $15-19$ & 3 & 3 \\
\hline & $20-24$ & $23(25.8)$ & $86(32)$ \\
\hline & $25-29$ & $32(36)$ & 91(33.8) \\
\hline & $30-34$ & $23(25.8)$ & $65(24.2)$ \\
\hline & $35-39$ & $7(7.9)$ & $21(7.8)$ \\
\hline & $>40$ & & \\
\hline
\end{tabular}

\section{Marital status}

\begin{tabular}{|c|c|c|}
\hline Married & 89 & 263(97.8) \\
\hline Divorced & 0 & 3 \\
\hline Widowed & 0 & 3 \\
\hline \multicolumn{3}{|l|}{ Maternal education } \\
\hline Cannot read and write & $26(29.2)$ & $132(49.1)$ \\
\hline Can read and write & 2 & $5(1.9)$ \\
\hline Primary school & $31(34.8)$ & $94(34.9)$ \\
\hline Secondary and above & $30(33.7)$ & $38(14.1)$ \\
\hline \multicolumn{3}{|l|}{ Husband education } \\
\hline Cannot read and write & $25(28.1)$ & $133(49.4)$ \\
\hline Can read and write & $5(5.6)$ & $22(8.2)$ \\
\hline Primary & $26(29.2)$ & $75(27.9)$ \\
\hline Secondary and above & $33(37.1)$ & $39(14.5)$ \\
\hline \multicolumn{3}{|l|}{ Occupation of mother } \\
\hline House wife & $22(24.7)$ & $99(36.8)$ \\
\hline Farmer & $45(50.6)$ & $150(55.8)$ \\
\hline Merchant & 11(12.4) & $12(4.5)$ \\
\hline Government employee & $10(11.2)$ & 3 \\
\hline Private employee & 1 & $5(1.9)$ \\
\hline \multicolumn{3}{|l|}{ Husband occupation } \\
\hline Farmer & $55(61.8)$ & $216(80.3)$ \\
\hline Merchant & $8(9)$ & $28(10.4)$ \\
\hline Government employee & $21(23.6)$ & $7(2.6)$ \\
\hline Private employee & $5(5.6)$ & $10(3.7)$ \\
\hline
\end{tabular}




\begin{tabular}{|c|c|c|}
\hline Daily laborer & 0 & $7(2.6)$ \\
\hline Student & 0 & 1 \\
\hline \multicolumn{3}{|l|}{ Wealth index } \\
\hline High & $37(41.6)$ & $84(31.2)$ \\
\hline Medium & $27(30.3)$ & $95(35.3)$ \\
\hline Low & $25(28.1)$ & $90(33.5)$ \\
\hline \multicolumn{3}{|l|}{ Family size } \\
\hline$<4$ & $60(67.4)$ & $162(60.2)$ \\
\hline $4-5$ & 13(14.6) & $38(14.1)$ \\
\hline$>5$ & $16(18)$ & $69(25.7)$ \\
\hline \multicolumn{3}{|l|}{ Birth order } \\
\hline 1 & $37(41.6)$ & $94(34.9)$ \\
\hline $2-3$ & $36(40.4)$ & $106(39.4$ \\
\hline$>3$ & $16(18)$ & $69(25.7)$ \\
\hline
\end{tabular}

Table 2: knowledge and attitude of mothers/caregivers towards GMP service utilization in Legambo district, South Wollo zone, Northern Ethiopia, 2020. 


\begin{tabular}{|c|c|c|}
\hline Variable & Case: $\mathrm{n}=89(\%)$ & Control: $\mathrm{n}=267(\%)$ \\
\hline \multicolumn{3}{|l|}{ Heard about GMP } \\
\hline Yes & $87(97.8)$ & 194(72.1) \\
\hline No & 2 & $75(20.9)$ \\
\hline \multicolumn{3}{|c|}{ Know the age groups for GMP } \\
\hline Yes & $77(86.5)$ & $193(75.4)$ \\
\hline No & $12(3.4)$ & $76(21.2)$ \\
\hline \multicolumn{3}{|c|}{ Know the starting time for GMP } \\
\hline Yes & $73(82)$ & 183(68) \\
\hline No & 16(18) & $86(32)$ \\
\hline \multicolumn{3}{|c|}{ Know interval between GMP } \\
\hline Yes & $82(92.1)$ & $175(65.1)$ \\
\hline No & $7(7.9)$ & $94(34.9)$ \\
\hline \multicolumn{3}{|c|}{ Know who to perform GMP } \\
\hline Yes & $84(94.4)$ & 182(67.7) \\
\hline No & $5(5.6)$ & $87(32.3)$ \\
\hline \multicolumn{3}{|c|}{ Know place of GMP services } \\
\hline Yes & $85(95.5)$ & $191(71)$ \\
\hline No & $4(4.5)$ & $78(29)$ \\
\hline \multicolumn{3}{|c|}{ GMP service has benefit for the child } \\
\hline Yes & 88(98.9) & $222(82.5)$ \\
\hline No & 1 & $47(17.5)$ \\
\hline \multicolumn{3}{|c|}{ Know when the growth chart is flattening } \\
\hline Yes & $70(78.7)$ & $135(50.2)$ \\
\hline No & $19(21.3)$ & 134(49.8) \\
\hline \multicolumn{3}{|c|}{ Know when the growth chart is rising } \\
\hline Yes & $70(78.7)$ & 134(49.8) \\
\hline No & $19(21.3)$ & $135(50.2)$ \\
\hline \multicolumn{3}{|c|}{ Know when the growth chart is falling } \\
\hline Yes & $70(78.7)$ & $133(49.4)$ \\
\hline No & $19(21.3)$ & 136(50.6) \\
\hline \multicolumn{3}{|l|}{ Knowledge } \\
\hline Good & $72(80.9)$ & $133(49.4)$ \\
\hline Poor & 17(19.1) & 136(30.6) \\
\hline \multicolumn{3}{|l|}{ Attitude } \\
\hline Favorable & $74(83.1)$ & $129(48)$ \\
\hline Unfavorable & 15(16.9) & $140(52)$ \\
\hline
\end{tabular}

Table 3- Health care service utilization related characteristics of mothers/caregivers in Legambo district, South Wollo zone, Northern Ethiopia, 2020. 


\begin{tabular}{|c|c|c|}
\hline Variable & Case: $\mathrm{n}=89(\%)$ & Control: $n=267(\%)$ \\
\hline \multicolumn{3}{|l|}{ Place of delivery } \\
\hline Home & $29(32.6)$ & $78(29)$ \\
\hline Health institution & $60(67.4)$ & 191(71) \\
\hline \multicolumn{3}{|l|}{ Immunization } \\
\hline Fully immunized & 86(96.6) & $262(97.4)$ \\
\hline Not immunized & $3(3.4)$ & $7(2.6)$ \\
\hline \multicolumn{3}{|l|}{ ANC utilization } \\
\hline Yes & $74(83.1)$ & $132(49.1)$ \\
\hline No & 15(16.9) & $137(50.9)$ \\
\hline \multicolumn{3}{|l|}{ PNC utilization } \\
\hline Yes & $68(76.4)$ & $117(43.5)$ \\
\hline No & $21(23.6)$ & $152(56.5)$ \\
\hline \multicolumn{3}{|l|}{ Counseling on GMP } \\
\hline Yes & 70(78.7) & $123(45.7)$ \\
\hline No & $19(21.3)$ & $146(54.3)$ \\
\hline \multicolumn{3}{|l|}{ Service quality } \\
\hline Good & $51(57.3)$ & $127(47.2)$ \\
\hline Poor & $38(42.7)$ & $142(52.8)$ \\
\hline \multicolumn{3}{|l|}{ Distance to health facility } \\
\hline$<1$ hour & $79(88.8)$ & $154(57.2)$ \\
\hline$\geq 1$ hour & $10(11.2)$ & $115(42.8)$ \\
\hline \multicolumn{3}{|l|}{ Mode of delivery } \\
\hline SVD & $85(95.5 \%)$ & $257(95.5 \%)$ \\
\hline instrumental & 0 & $5(2.6)$ \\
\hline $\mathrm{C} /$ section & $4(1.9)$ & $7(4.5)$ \\
\hline \multicolumn{3}{|l|}{ Counseled on Nutrition } \\
\hline Yes & 88(98.9) & $32(11.9)$ \\
\hline No & 1 & $237(88.1)$ \\
\hline
\end{tabular}

Vitamin A supplementation 


\begin{tabular}{ccc} 
Yes & $86(96.6)$ & $45(16.7)$ \\
\hline No & 3 & $224(83.3)$ \\
\hline Birth order & & \\
\hline 1 & $37(41.6)$ & $94(34.9)$ \\
\hline $2-3$ & $36(40.4)$ & $106(39.4)$ \\
\hline
\end{tabular}

Table 4- Predictors of GMP services utilization among children 0-23 months of age in Legambo district, South Wollo zone, Northern Ethiopia, 2020. 


\begin{tabular}{|c|c|c|c|c|}
\hline \multirow[t]{2}{*}{ Variable } & \multirow[t]{2}{*}{ Cases } & \multirow[t]{2}{*}{ Controls } & \multicolumn{2}{|c|}{$95 \%$ confidence interval } \\
\hline & & & COR & AOR \\
\hline \multicolumn{5}{|l|}{ Mother educational level } \\
\hline Illiterate & $26(29.2 \%)$ & $132(49.1 \%)$ & 1 & 1 \\
\hline read and write & $2(2.2 \%)$ & $5(1.9 \%)$ & $2.03(0.37-11.04)$ & $1.32(0.19-9.17)$ \\
\hline Primary & $31(34.8 \%)$ & $94(34.9 \%)$ & $1.67(0.93-3.00)$ & $1.29(0.52-3.22)$ \\
\hline Secondary and above & $30(33.7 \%)$ & $38(14.1 \%)$ & $4.01(2.12-7.58)$ & $1.96(0.68-5.69)$ \\
\hline \multicolumn{5}{|l|}{ Partner education } \\
\hline Illiterate & $25(28.1 \%)$ & $133(49.4 \%)$ & 1 & 1 \\
\hline read and write & $5(5.6 \%)$ & $22(8.2 \%)$ & $1.21(0.42-3.49)$ & $0.89(0.23-3.50)$ \\
\hline Primary & $26(29.2 \%)$ & $75(27.9 \%)$ & $1.84(0.99-3.42)$ & $1.25(0.49-3.19)$ \\
\hline Secondary and above & $33(37.1 \%)$ & $39(14.5 \%)$ & $4.5(2.39-8.46)$ & $1.87(0.68-5.13)$ \\
\hline \multicolumn{5}{|l|}{ Child age in months } \\
\hline $0-5$ & $7(7.9 \%)$ & $67(24.9 \%)$ & 1 & 1 \\
\hline $6-11$ & $17(19.1 \%)$ & $67(24.9 \%)$ & $2.43(0.95-6.24)$ & 2.67-(0.91-7.85) \\
\hline $12-17$ & $35(39.3 \%)$ & $74(27.5 \%)$ & $4.53(1.89-10.87)$ & $3.45(1.26-9.41)^{*}$ \\
\hline $18-23$ & $30(33.7 \%)$ & $61(22.7 \%)$ & $4.70(1.93-11.49)$ & $4.38(1.53-12.49)^{* *}$ \\
\hline \multicolumn{5}{|l|}{ Maternal knowledge } \\
\hline Good & $72(80.9 \%)$ & $133(49.4 \%)$ & $4.33(2.42-7.73)$ & $2.42(1.23-4.75)^{*}$ \\
\hline Poor & $17(19.1 \%)$ & $136(30.6 \%)$ & 1 & 1 \\
\hline \multicolumn{5}{|l|}{ Maternal attitude } \\
\hline Favorable & $74(83.1 \%)$ & $129(48.0 \%)$ & $5.35(2.92-9.79)$ & $2.45(1.20-4.98) *$ \\
\hline Unfavorable & $15(16.9 \%)$ & $140(52.0 \%)$ & 1 & 1 \\
\hline \multicolumn{5}{|l|}{ Counseling on GMP } \\
\hline Yes & $70(78.7 \%)$ & $123(45.7 \%)$ & $4.37(2.49-7.66)$ & $2.34(1.19-4.56)^{*}$ \\
\hline No & $19(21.3 \%)$ & $146(54.3 \%)$ & 1 & 1 \\
\hline \multicolumn{5}{|l|}{ Access to media } \\
\hline Yes & $52(58.4 \%)$ & $114(42.4 \%)$ & $1.91(1.18-3.11)$ & $0.92(0.48-1.77)$ \\
\hline No & $37(41.6)$ & $155(57.6 \%)$ & & \\
\hline \multicolumn{5}{|l|}{ Distance to health facility } \\
\hline$<1$ hour & $79(88.8 \%)$ & $154(57.2 \%)$ & $5.89(2.93-11.89)$ & $4.53(1.99-10.28)^{* *}$ \\
\hline$>1$ hour & $10(11.2 \%)$ & $115(42.8 \%)$ & 1 & 1 \\
\hline \multicolumn{5}{|l|}{ Service quality } \\
\hline Good & $51(57.3 \%)$ & $127(47.2 \%)$ & $1.50(0.93-2.43)$ & $1.12(0.60-2.07)$ \\
\hline Poor & $38(42.7 \%)$ & $142(52.8 \%)$ & 1 & 1 \\
\hline \multicolumn{5}{|l|}{ ANC service utilization } \\
\hline Yes & $74(83.1 \%)$ & $132(49.1 \%)$ & $5.12(2.79-9.37)$ & $2.46(1.18-5.16)^{*}$ \\
\hline No & $15(16.9 \%)$ & $137(50.9 \%)$ & 1 & 1 \\
\hline
\end{tabular}


PNC service utilization

\begin{tabular}{ccccc}
\hline Yes & $68(76.4 \%)$ & $117(43.5 \%)$ & $4.20(2.44-7.26)$ & $1.89(0.95-3.62)$ \\
\hline No & $21(23.6 \%)$ & $152(56.5 \%)$ & 1 & 1 \\
\hline
\end{tabular}

*P-value $<0.05$; ** P-value $<0.001$

\section{Figures}

\section{child age in months}

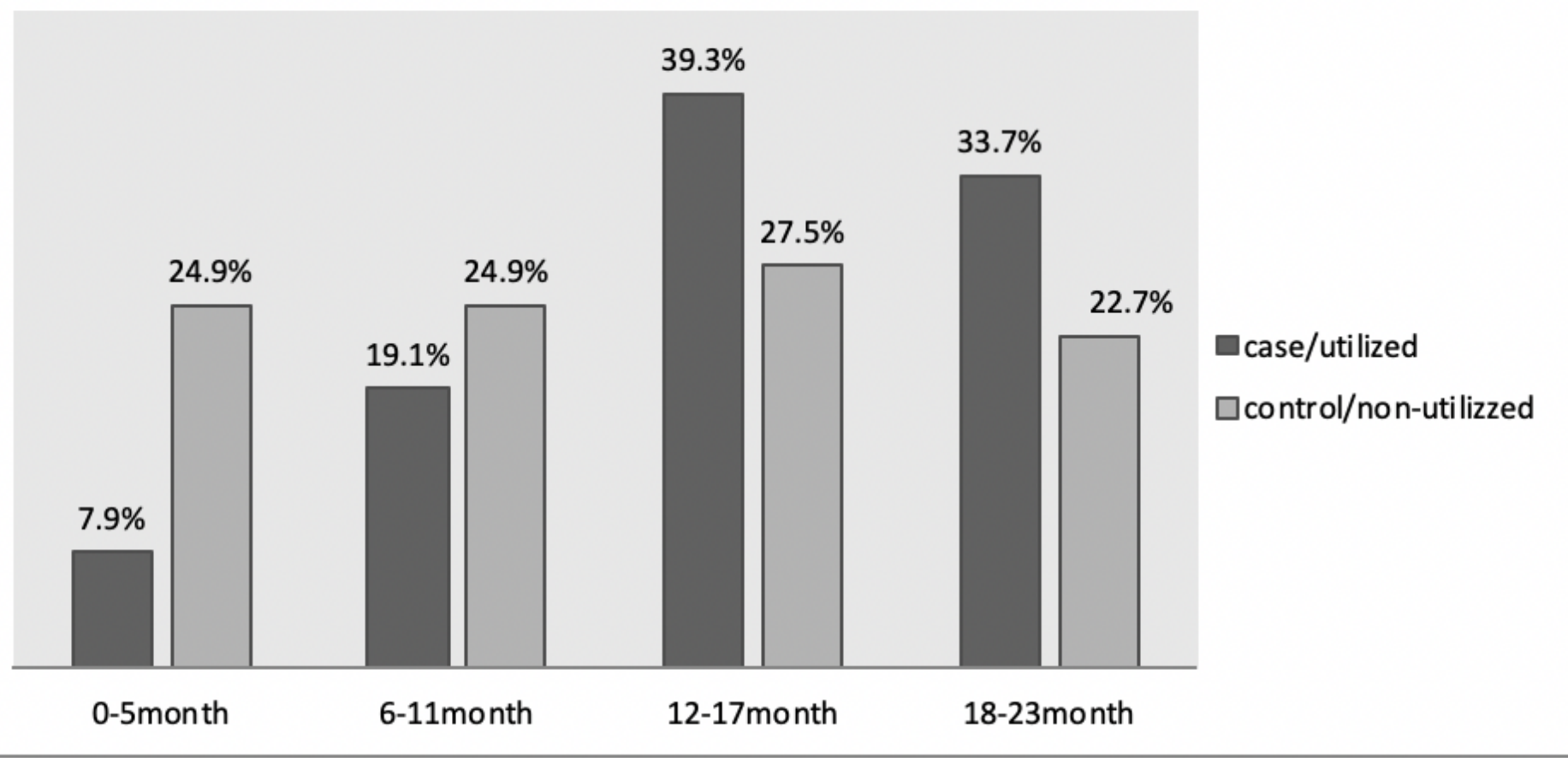

Figure 1

Growth Monitoring and Promotion service and child age in Legambo district, South Wollo zone, Northern Ethiopia, 2020. 